\title{
“O futuro não pertence aos globalistas": Donald Trump e a instrumentalização política do nacionalismo.
}

\author{
"The future does not belong to globalists": Donald Trump and the political instrumentalization of \\ nationalism.
}

DOI: https://doi.org/10.22456/2178-8839.106661

Thiago Godoy Gomes de Oliveira Programa de Pós-Graduação em Relações Internacionais San Tiago Dantas (UNESP, UNICAMP, PUC-SP), São Paulo, Brasil thiagogodoy_oliveira@hotmail.com

Lucas Amaral Batista Leite Programa de Pós-Graduação em Relações Internacionais San Tiago Dantas (UNESP, UNICAMP, PUC-SP), São Paulo, Brasil leite.ri@gmail.com

\section{Resumo}

Após a eleição à presidência de Donald Trump em 2016 o debate internacional acerca do nacionalismo ganhou elevada importância. O elemento mais inédito no caso norte-americano corresponde ao fato de oprincipal agente globalizador, agora, colocar-se contra regimes internacionais dos quais liderou a construção. Este trabalho busca compreender como Trump buscou instrumentalizar e potencializar o sentimento nacionalista no país em seu favor. A pesquisa será realizada a partir da realização de um levantamento bibliográfico de caráter exploratório. Fará uso também da apuração e análise dados de opinião pública coletados por agências especializadas, como o Pew Research Center e Gallup, além de fontes primárias, como discursos proferidos por Trump. O apuramento dos dados, juntamente com a análise realizada, demonstra que o nacionalismo, historicamente identificado como um termo que carrega um significado negativo desde o pós-Segunda Guerra, ganha espaço na esfera doméstica e na política externa dos Estados Unidos. Nessa dinâmica, Trump busca explorar e potencializar sentimentos nacionalistas nas esferas econômica, cultural e étnica.

Palavras-chave: Nacionalismo; Donald Trump; Política Externa;

\section{Abstract}

After the election to the presidency of Donald Trump in 2016, the international debate about nationalism took on a greater importance. The most curious element in the North American case is that the main globalizing agent is now opposing international regimes of which he led the construction. This work seeks to understand how Trump, facing the country's political scenario, sought to instrumentalize and enhance the nationalist sentiment in the country in his favor. The research will be carried out by conducting a bibliographic and exploratory surve. It will use public opinion data collected by specialized agencies, such as Pew Research Center and Gallup, and primary sources, such as speeches, delivered by Trump. The collection of data, together with the analysis carried out, demonstrate that nationalism, historically identified as a term that carries a negative meaning since the post-World War II, gains more space in the domestic sphere and in the foreign policy of the United States. In this dynamic, Trump seeks to explore and enhance nationalist sentiments in the economic, cultural and ethnic spheres.

Keywords: Nationalism; Donald Trump; Foreign Policy; 


\section{Introdução}

Ao longo da última década um embate entre o "globalismo" e o nacionalismo tomou forma, não somente nos Estados Unidos, mas em diversas nações. Comumente apontado como o marco inicial de um movimento anti-globalista internacional, o referendo pró-Brexit em 2016 no Reino Unido não obteve o mesmo efeito de contágio que as eleições presidenciais norte-americanas do mesmo ano, uma vez que, por representar o "líder do mundo livre", seu grau de influência econômica, política e cultural é maior. Após a eleição de Donald Trump, discursos de teor nacionalista e de protecionismo econômico ganharam maior projeção global. Lideranças como a de Steve Bannon, junto de seu “Movimento”, alcançaram o mainstream internacional e influenciaram campanhas eleitorais na Europa e no Brasil - tendo em vista encontros ocorridos com a ala bolsonarista antes e após as eleições de 2018 no Brasil (BULLA; LEOPOLDO, 2019). Após passar o primeiro ano de seu mandato utilizando-se mais do termo "patriotismo", Trump se autoproclamou como um nacionalista em um comício em Houston, Texas, em outubro de 2018: "Você sabe o que eu sou? Eu sou nacionalista, O.K. Eu sou nacionalista. Nacionalista! Usem essa palavra! Usem essa palavra!” (TRUMP, 2018 apud BAKER, 2018, tradução nossa $a^{2}$.

Este artigo busca compreender como Trump buscou instrumentalizar e potencializar o sentimento nacionalista no país em seu favor. Queremos também demonstrar como esse nacionalismo se manifesta, principalmente, na política externa norte-americana. A pesquisa será realizada a partir da realização de um levantamentobibliográfico e terá caráter exploratório, tendo como recorte temporal a campanha eleitoral de Trump de 2016 até o final de seu mandato. Será feita a apuração e análise dados de opinião pública coletados por agências especializadas, como o Pew Research Center e Gallup, e de falas e discursos proferidos pelo então presidente dos Estados Unidos. Primeiramente, serão abordados os conceitos de nacionalismo, para que, na segunda parte, possamos analisar a percepção popular acerca desses sentimentos e a forma com que Trump os utiliza na esfera de seu discurso político. Na terceira parte, será analisada a influência do nacionalismo na política externa contemporânea do país, realizando comparativos com os discursos e práticas do presidente. Este trabalho busca contribuir para uma elucidação dos distintos significados acerca do nacionalismo, sua inserção no imaginário coletivo norte-americano e como foi instrumentalizado politicamente pelo presidente. Ao final, será realizada uma breve conclusão acerca dos resultados apresentados e qual a sua significância para a política doméstica e externa dessa nação.

\section{Sobre o nacionalismo}

Conceituar o nacionalismo nos Estados Unidos apresenta-se como um desafio metodológico, uma vez que a experiência norte-americana diverge completamente da experiência europeia com o nacionalismo. Nesse sentido, esse trabalho parte das abordagens de Benedict Anderson, Ernest Gellner, Thongchai Winichakul e Eric Hobsbawm, uma vez que suas contribuições para os estudos do nacionalismo nos auxiliam a compreender suas dinâmicas contemporâneas. Na segunda parte serão introduzidas as tipologias de nacionalismo nos Estados Unidos.

Benedict Anderson (2008) classifica o nacionalismo não como uma força negativa ou positiva, mas sim como uma comunidade política imaginada. Logo, elementos de união entre indivíduos correspondem mais a aspectos socioculturais, como uma língua e valores em comum, do que o elo com o território que ocupam. As lápides e mausoléus de soldados desconhecidos exemplificam a conexão proveniente do nacionalismo apontada pelo autor, já que muitas dessas tumbas são preenchidas com restos mortais não identificados de soldados de mesma ou de diferentes nacionalidades ou estão vazias. No entanto, cada nação, com esse ritual cerimonial, clama a nacionalidade do soldado para si e, logo, para sua

\footnotetext{
1 Compreendido de forma negativa pela extrema direita como uma ideologia que privilegia fóruns internacionais e instituições multilaterais em detrimento da independência e identidade de Estados-nação (MANNING, 2019).

2 You know what I am? I'm a nationalist, O.K.? I'm a nationalist. Nationalist! Use that word! Use that word! (TRUMP, 2018 apud BAKER, 2018).
} 
comunidade. A nação, segundo Anderson, é imaginada justamente pelo fato de a maioria de seus integrantes não se conhecerem, mas ainda existir a partir de um forte senso de fraternidade que precede as características em comum criadas ao longo dos tempos (p. 6-7).

Para Ernest Gellner (2015), a nação nãoé um fenômeno natural, mas algo necessário para unificar o Estado a uma cultura, sendo sua padronização uma necessidade do nacionalismo. Este surge a partir do reconhecimento de seus membros entre si enquanto compatriotas dotados de direitos e deveres comuns, não de quaisquer características préexistentes compartilhadas. A nação, dessa forma, seria uma entidade artificialmente fabricada com base no reconhecimento mútuo entre seus membros. Thongchai Winichakul dá continuidade às premissas postuladas por Anderson e Gellner e insere a variável territorial. Para o autor, o nacionalismo depende da natureza finita da demarcação fronteiriça, que delimita o que faz parte da nação e os contornos da identidade nacional. O autor reconhece a importância que o território possui na produção de uma identidade coletiva e da soberania nacional, postulando que o território é uma construção artificial a partir da cartografia e de discursos geográficos (WINICHAKUL, 2015 apud FINKEL, 2016).

Assim como Anderson, Eric Hobsbawm (1991) afirma que qualquer grupovolumoso de indivíduos que tratam a si mesmos como uma nação devem ser reconhecidos como tal. Hobsbawm contribui para os estudos do nacionalismo por pontuar que o reconhecimento de laços, juntamente com uma identidade artificialmente fabrica da ao longo do tempo, definem uma nação. Dentro dessa perspectiva, as nações não se consolidam com base em laços pré -existentes entre um grupo, elas são reflexo de determinado contexto social e econômico, modificando-se a partir desse contexto e da homogeneização de práticas. Por sua origem marxista, o autor aponta que o entendimento de uma nação deve se dar de baixo para cima, uma vez que demonstra que a ideologia nacional do establishment político (ou da classe dominante) não reflete a ideologia nacional da classe trabalhadora. Hobsbawm aponta que cada grupo e classe possui uma maneira pela qual caracteriza suaidentidade nacional, sendo possível que a concepção acerca do que define uma nação mude de maneira gradual ou repentina (p.159-170).

Por ser um fenômeno que encontra suas origens desde o século XVIII, diferentes tipologias foram empregadas para tentar explicar distintas manifestações do nacionalismo. Tendo como foco deste trabalho a experiência norte americana, serão elucidados o nacionalismoétnico, cultural, econômico e o cívico, uma vez que são apresentados como os quatro componentes do nacionalismo norte-americano (MOTYL, 2000, p. 17-8). O nacionalismo étnico, segundo o sociólogo Anthony D. Smith, origina-se a partir da

[...]nação como uma comunidade de cultura e história, com um laço de solidariedade que se assemelha ao vínculo familiar. Aqui, um mito de ancestralidade comum substitui a residência em uma pátria histórica como critério de associação nacional; genealogia em vez de território define a nação étnica. Da mesma forma, as culturas vernáculas, notadamente a língua e os costumes, são mais valorizadas do que a igualdade legal e a mobilização popular do que a cidadania. Finalmente, no lugar de uma cultura de massa cívica, os nacionalismos étnicos exaltam a história nativa e uma cultura étnica mais circunscrita (HUTCHINSON;SMITH, 1994, p. 188).

O nacionalismo cultural, apesar de visar a preservação da identidade cultural de uma nação, não se prende a questões ancestrais ou raciais, mas a uma tradição histórico-cultural. Logo, a diversidade racial pode se fazer presente no nacionalismo cultural, tendo como exemplo contemporâneo sua presença no bloco da União Europeia, assim como na formação dos Estados Unidos (NIELSEN, 1999, p. 120 -8). Por sua vez, o nacionalismo econômico prima pela defesa dos interesses econômicos de uma nação sob a perspectiva de ganhos absolutos em um jogo de soma -zero ${ }^{3}$, mesmo que isso signifique prejudicar até mesmo nações aliadas. Em um cenário de interdependência econômica e de fóruns econômicos internacionais, mesmo que em níveis desiguais, as nações presentes acabam obtendo benefícios nessa dinâmica. Frente ao

\footnotetext{
${ }^{3}$ Preceito de uma situação na qual, se uma parte ganha determinada vantagem, a outra deve sofre uma desvantagem equivalente (CO LLINS, 2020).
} 
nacionalismo econômico, a cooperação presente no liberalismo econômico estabelecida desde Bretton Woods ${ }^{4}$ perde importância para nações no qual esse tipo de nacionalismo se faz presente, gerando um cenário de competição e desconfiança (GLADDING, 2018).

Por fim, o nacionalismo cívico, também chamado de liberal, representa uma forma de nacionalismo que não se baseia na valorização da identidade a partir de aspectos culturais ou étnicos, mas sim nas instituições e princípios liberais da nação. A participaçãoé, portanto, voluntária, uma vez que, somente com a internalização desses valores, seria possível tomar parte nela. Assim, diferentemente das outras modalidades, é uma forma de nacionalismo mais inclusivo quevaloriza a liberdade, igualdade e os direitos individuais.

No que tange à história dos Estados Unidos, o nacionalismo cívico serviu de fonte de influência para a criação de um sistema representativo no país, uma vez que seus preceitos estãoligados à criação de instituições democráticas fortes (LIEVEN, 2012, p.15-9). O sentimento de nacionalismo cívico é similar à ideia de patriotismo a partir de elementos como a liberdade, igualdade e justiça. Todavia, a diferença entre os dois conceitos reside na condição na qual o nacionalismo se manifesta: o sentimento de superioridade de uma nação perante outra. Por isso, o nacionalismo cívico alinha -se mais ao sentimento nacional nos Estados Unidos, uma vez que exemplos históricos como o America is the number one ou America First - que precede a campanha de Trump - denotam a superioridade nacional perante outros Estados (KOSTERMAN; FESCHBACH1989, p. 271 apud BONIKOWSKI; DiMAGGIO, 2016, p. 4).

Há, contudo, uma certa recusa nacional em aproximar-se de qualquer tipo de nacionalismo, preferindo caracterizar o nacionalismo cívico como patriotismo. Isso se deve a duas razões: o excepcionalismo norte -americano e outros exemplos históricos de nacionalismo (FULLER, 2006, p. 2-4). O excepcionalismo justifica aspirações e manifestações nacionalistas como algo além do nacionalismo, como uma responsabilidade missionária do país com o mundo.

O excepcionalismo conota, portanto, um elemento de superioridade, uma qualidade intangível, mas claramente reconhecível, que podemos identificar em gênios e outras pessoas de extraordinário talento no nível individual, por exemplo, e que está enraizada no que às vezes é chamado de "gênio". "da organização política da América no nível coletivo (McCARTNEY, 2004,p. 403, tradução nossa ${ }^{5}$ ).

Por outro lado, as experiências históricas do país com o nacionalismo manifestaram-se no antagonismo com aspirações nacionais de colonizadores europeus, movimentos nacionais separatistas e racistas no período da Guerra Civil - os Confederados - e a ascensão do nazifascismo na Europa. Pela percepção negativa acerca do que é o sentimento nacionalista, devida em grande parte pelos movimentos nazifascistas no início do séculoXX, o nacionalismo, mesmo que presente aolongo da história do país no excepcionalismo norte-americano, não estáinserido explicitamente no imaginário coletivo dos Estados Unidos como, por exemplo, o conceito de patriotismo (BONIKOWSKI; DiMAGGIO, 2016, p. 2 -3).

\section{O nacionalismo na esfera doméstica}

No período de campanha à presidência, entre junho de 2015 e novembro de 2016, Trump realizou um total de 323 comícios pelo país, com presença estimada de 1,4 milhões de apoiadores. Mesmo após eleito, entre dezembro de 2016 e dezembro de 2019, Trump ainda realizou 79 comícios no país, sendo 8 em 2016 (os chamados victory rallies), 10 em 2017 (post-inauguration rallies), 40 em 2018 (midterm rallies) e 21 em 2019 (sendo seis do período de pré -campanha à reeleição e quinze no período das primárias). Diferentemente de seus antecessores, os comícios de Trump são realizados não

\footnotetext{
${ }^{4}$ Sistema monetário internacional organizado por delegados de 44 nações em Bretton Woods, New Hampshire, em julho de 1944 . Foi acordada a criação do Fundo Monetário Internacional, que veio a se tornar o Banco Mundial. O sistema de conversibilidade da moeda que emergiu de Bretton Woods durou até 1971 (FEDERAL RESERVE HISTORY, 2013).

${ }^{5}$ Exceptionalism, therefore, connotes an element of superiority, an intangible but clearly recognizable quality that we can identify in geniuses and other people of extraordinary talent on the individual level, for example, and that is rooted in what is sometimes referred to as the "genius" of America's political organization at the collective level (McCARTNEY, 2004, p. 403).
} 
somente com a finalidade eleitoral-partidária ou de mobilização popular para uma política pública, mas também como uma forma de manter um contato contínuo com seu eleitorado pela esfera discursiva (BENDER, 2019).

A escolha em optarmos pelos comícios em detrimento de outras fontes de contato direto com o público, como o Twitter, justifica-se pelo fato de os comícios contínuos, além de serem inusitados, limitam o público quase que exclusivamente a apoiadores do presidente, sendo uma esfera na qual Trump dialoga e recebe um feedback imediato de seus próprios eleitores, apresentando-se como uma possibilidade de análise viável no que tange a identificação da instrumentalização do nacionalismo no país. Paralelamente, os pronunciamentos de Trump serão complementados com as percepções populares acerca de temas como o multiculturalismo, imigração, identidade nacional, relações raciais, dentre outros.

A Figura 1 elucida as percepções divididas dentro da sociedade norte-americana acerca do multiculturalismo. Apesar de haver uma visão majoritariamente positiva em relação ao papel de imigrantes no país e na construção da identidade norte-americana, mais da metade da parcela próxima de um espectro mais conservador observa imigrantes como ameaça à identidade nacional e como peso econômico, ao passo que, na parcela mais liberal, mais de metade observa a imigração de forma extremamente positiva. Ao abordar a questão do islamismo, 49\% não consideram como sendo uma ameaça à segurança nacional, ao passo que $43 \%$ o fazem - sendo que desses, $79 \%$ do núcleo mais conservador do país reconhecem como uma grave ameaça (PEW RESEARCH CENTER, 2017b).

\section{Imagem 1: Visões por inclinação ideológica acerca de imigrantes}
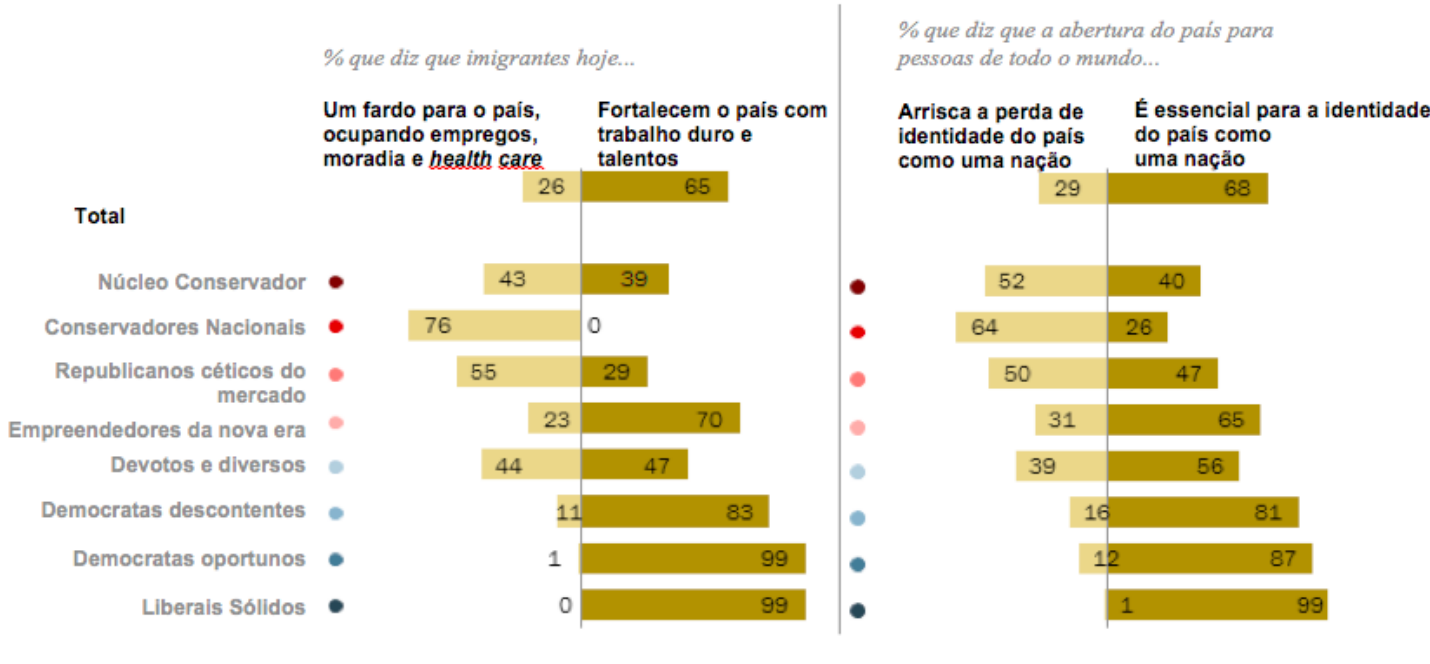

Fonte: Adaptado pelos autores, com base em Pew Research Center (2017a).

Nesse quesito Trump promove o reforço da imagem do imigrante como uma ameaça à segurança nacional do país, já que em comícios realizados entre fevereiro de 2017 e agosto de 2019, utilizou 219 vezes o termo "estrangeiro não naturalizado”, 189 vezes “criminoso”, 43 vezes que deveriam “dar o fora do país”, 34 vezes “animal”, 32 vezes “matador”, 31 vezes "predador" e 19 vezes relacionou imigrantes a "invasores" (BUCHHOLZ, 2019). Além disso, o combate violento ao imigrante é naturalizado de forma descontraída em seus comícios. Durante um comício realizado em 8 de maio de 2019 na região de Panhandle no estado da Flórida, enquanto falava sobre a necessidade de impedir que imigrantes hispânicos pudessem comprar armas no país, Trump foi interrompido pelo grito de um apoiador pedindo que atirassem nos imigrantes na fronteira. O comentário, seguido de uma risada de Trump e da plateia, foi respondido com um sorriso: "Só no Panhandle você pode se safar com essa afirmação... Apenas no Panhandle!” (TRUMP, 2019 apud DIAMOND, 2019, traduçãonossa6).

\footnotetext{
${ }^{6}$ That's only in the Panhandle you can get away with that statement... Only in the Panhandle! (TRUMP, 2019 apud DIAMOND, 2019).
} 
Sentimentos nacionalistas originam-se de forma orgânica e não necessitam de uma organização ou liderança clara, mas, consequentemente, acabam gerando ou legitimando novas lideranças. Essas novas lideranças, dependendo do grau de radicalismo do nacionalismo em curso, podem realçar a valorização de tendências mais autoritárias. Segundo o Public Religion Research Institute (PRRI), há uma percepção na população de que, uma vez que o país aparentemente saiu dos eixos, é necessário um líder que quebre algumas regras para consertar a atual situação. No que tange à classe branca trabalhadora e branca com ensino superior, 60\% e 32\% aprovam, respectivamente, a percepção descrita acima. Mesmo com uma reprovação considerável da parcela branca com ensino superior (67\%), há uma divisão quando abordada a população como um todo: $49 \%$ e 50\% da população total concordam e discordam da afirmação, respectivamente. Logo, um flerte nacional com o autoritarismo destoa dos princípios patriotas de valorização das instituições e da liberdade, e demonstra uma perda de força da tradição do nacionalismo cívico (COX et al, 2017). Outro aspecto que evidência tendências do nacionalismo cultural e étnico nos Estados Unidos estão presentes na Figura 2.

Em relação a essa “assertividade” esperada de um líder, Trump busca deslegitimar instituições democráticas no país, como nas ocasiões em que afirmou que não aceitaria resultados eleitorais desfavoráveis - o que veio a acontecer em 2020 - e que há um governo paralelo que busca minar a democracia, como disse em um comício no dia 6 de setembro de 2018 em Billings, Montana: "operadores não eleitos de um estado profundo que desafiam os eleitores para promoverem suas próprias agendas secretas são verdadeiramente uma ameaça à democracia” (TRUMP, 2019 apud WOLF, 2019, tradução nossa7). Além de atacar e deslegitimar opositores políticos, classificando os democratas como "o partido do crime" em um comício em Rochester, Minnesota (TRUMP, 2018 apud LAMBERT, 2018) e constantemente utilizando o termo "Hillary desonesta 8" para se referir à sua oponente democrata à presidência em 2016, estimulando os cantos de “prenda ela!” de seus apoiadores, como ocorreu em um comício em Cincinnati, Ohio (TRUMP, 2016 apud FRAZIN, 2019).

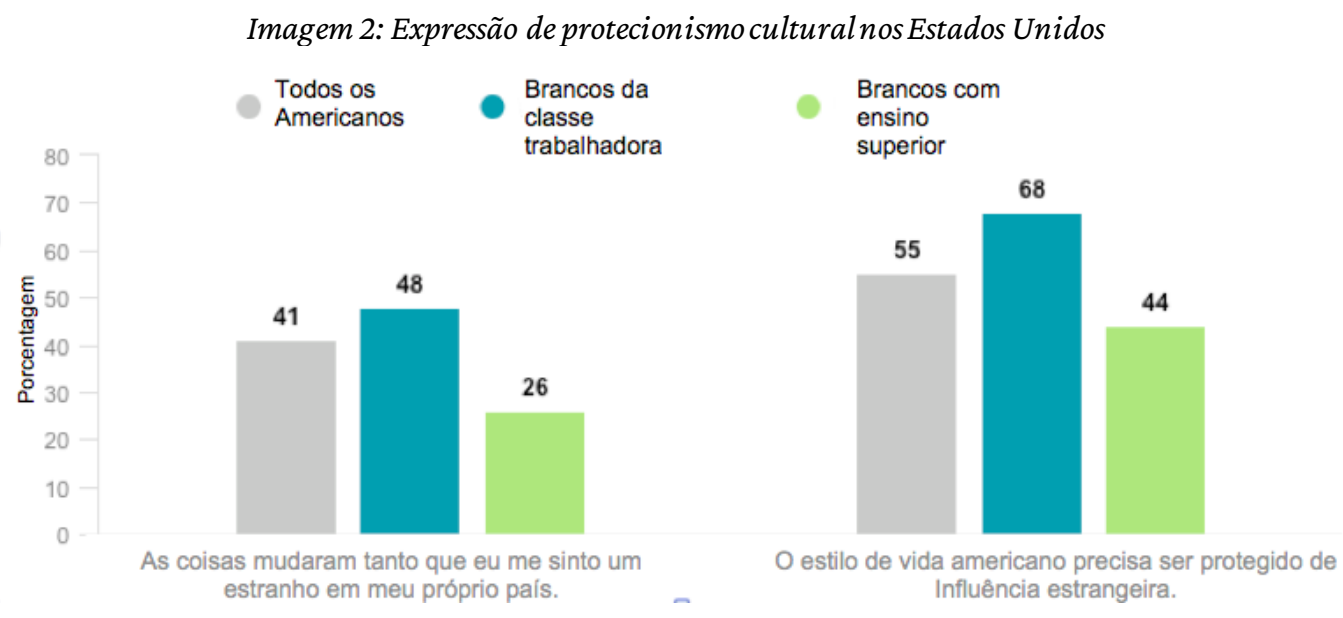

Fonte: Adaptado pelos autores, com base em Cox et al (2017).

Apesar de os números serem mais expressivos em relação à parcela branca com menos escolaridade, no quadro geral da população norte-americana quase metade dos norte-americanos sentem-se "estranhos" na própria nação e mais da metade acha que o american way of life deve ser livre de influências externas. Somado à questão de protecionismo cultural $^{9}, 70 \%$ da população crê que falar o idioma local é um elemento crucial para ser um verdadeiro americano (PEW RESEARCH CENTER, 2017b), contudo, pouco mais da metade dos imigrantes (52,2\%) possue m proficiência no inglês. Todavia, fatores religiosos são pouco significativos para a população total, justamente por apenas $32 \%$ julgarem ser

\footnotetext{
${ }^{7}$ Unelected deep state operatives who defy the voters to push their own secret agendas are truly a threat to democracy (TRUMP, 2018 apud WOLF, 2019).

${ }^{8}$ Crooked Hillary.

9 Entendido como o impulso de um grupo em preservar aspectos de sua cultura frente uma força externa ou doméstica que ameaça a condição de existência de sua cultura (BURRI, 2012, p. 182-3).
} 
adeptos de religião cristã como elemento principal para ser um verdadeiro americano (PEW RESEARCH CENTER, 2019b), o que realça mais aspectos culturais do que religiosos.

Frente às mudanças demográficas em curso e temas específicos em relação à identidade do país, com base na inclinação partidária ${ }^{10}$, duas conclusões decorrem: há uma clara ansiedade de uma considerável parcela da população frente essas mudanças, uma vez que 58\% apontam as relações raciais no país como ruins após a eleição de Trump (PEW RESEARCH CENTER, 2019b), além de um medo expressivo em relação a preservação de sua identidade, já que mais da metade de brancos, negros, latinos e asiáticos acreditam que existe uma discriminação contra seu grupo atualmente (HARVARD T. H. CHAN SCHOOL OF PUBLIC HEALTH; NPR, 2018, p. 4).

Trump busca explorar a questão identitária acerca de quem são os "reais americanos” no país, alienando opositores políticos como traidores dessa identidade ao mesmo tempo em que reforça, mesmo que de formaimplícita,uma identidade majoritariamente branca. Em um comício em Minnesota em setembro de 2020, o presidente classificou a congressista democrata somali-americana, Ilhan Omar, como corrupta e desonesta, deixando claro que, mesmo servindo ao corpo político do país, ela não poderia tecer críticas à presidência “Então ela nos diz como administrar nosso país, você acredita? Como diabos Minnesota a elegeu? O que diabos há de errado com vocês? O que diabos aconteceu?" (TRUMP, 2020 apud LEVIN, 2020, tradução nossa ${ }^{11}$ ). Nesse sentido, Trump concentra a identidade nacional em aspectos culturais e étnicos, distanciando o sentimento nacional de um na cionalismo cívico.

\section{Nacionalismo e a política externa}

Para que possamos explorar a política externa sob essa perspectiva é necessário resgatarmos o conceito do excepcionalismo norte. Outrossim, o nacionalismo em política externa dos Estados Unidos se materializa por meio de dois elementos: a religião civil americana, ou american civil religion, e o iluminismo. O primeiro permite que os americanos expressem seus sentimentos patrióticos em linguagem religiosa e vice-versa, imaginando que existe uma consistência fundamental entre suas preferências políticas e os imperativos teológicos de sua fé. Nesse sentido, implementam uma aura de aprovação e de providência divina em ações de política externa, sempre evocando uma confiança inabalável e um destino nacional providencial. Já seu caráter iluminista corresponde a uma aplicação dos conceitos europeus à nova experiência americana. Sendo os Estados Unidos uma tábularasa, seria possível dar início ao “novo começo” proposto pela corrente iluminista europeia, propagando a liberdade individual e o progresso através da razão. A América seria a chance de um novo início livre das amarras europeias, sendo o ponto de partida para a proliferação da liberdade a partir do experimento norte-americano-que contribui para o caráter missionário do excepcionalismo (McCARTNEY, 2004,p. 4046).

Com uma presença notória na formação histórica dos Estados Unidos, aspectos nacionalistas também sempre estiveram presentes na política externa do país. Colin Dueck (2019) aponta que o nacionalismo conservador é uma tradição forte na história da política exterior, sendo o Farewell Address de George Washington uma das principais evidências. No que tange à política externa, o documento de Washington aponta que o país deveria evitar alianças permane ntes, preservando a capacidade de liberdade de ação, ou freedom of action. Esse elemento viria a se tornar um comportamento marcante na política externa até as as duas grandes guerras mundiais no início do século XX, que resultaram na reformulação dessas diretrizes nas presidências de Woodrow Wilson e Franklin Roosevelt. Mesmo com uma participação mais ativa dos Estados Unidos no cenário internacional, o aspecto de freedom of action ainda continuou presente em diversos presidentes do Grand Old Party-como é chamadoo Partido Republicano.

\footnotetext{
${ }^{10}$ Com $84 \%$ dos democratas observando a imigração como um aspecto positivo, ao passo que $42 \%$ dos republicanos como algo negativo (PEW RESEARCH CENTER, 2017c)

${ }^{11}$ Then she tells us how to run our country, can you believe it? How the hell did Minnesota elect her? What the hell is wrong with you people? What the hell happened? (TRUMP, 2020, apud LEVIN, 2020).
} 
Dessa forma, Dueck (2019) aponta que a atual política externa de Donald Trump não está, de certa maneira, destruindo tradições, mas sim restaurando com mais força uma tradição histórica. Nosso objetivo é identificar como a retomada dessa tradição se materializa em ações de política externa durante ogoverno de Donald Trump. Para tanto, será realizada uma exposição acerca da percepção popular em relação a temas de política exterior para que, posteriormente, seja realizada uma comparação com os discursos e ações empíricas tomadas pela administração Trump.

Um levantamento de maio de 2016 feito pelo Pew Research Center apontou que 46\% dos entrevistados (sendo $76 \%$ republicanos e $26 \%$ democratas) concordam que o país é menos importante e poderoso do que há dez anos. Quando perguntados se o país é menos respeitado internacionalmente, $61 \%$ (sendo $71 \%$ republicanos e 59\% democratas) deram uma resposta afirmativa (DOHERTY, 2016). Em outrolevantamento realizado antes da posse de Trump, buscou-se mapear as principais ameaças exteriores de acordo com a sociedade norte-americana: para os republicanos, o ISIS (86\% do total e $89 \%$ dos mais conservadores), o programa nuclear norte-coreano (66\% do total e 67\% dos mais conservadores), maior número de refugiados deixando o Iraque e a Síria (63\% do total e 70\% dos mais conservadores) e o poder da China (58\% do total e 59\% dos mais conservadores) representaram maiores ameaças para esse grupo do que para democratas. Nesse mesmo período, somente $41 \%$ dos republicanos consideravam a Rússia como uma séria ameaça, ao passo que $67 \%$ dos democratas a consideravam. Todavia, ambos possuem uma visão não favorável à figura do presidente russo, Vladimir Putin (PEW RESEARCH CENTER, 2017d).

Mais de um ano depois, outro levantamento do Pew Research, representado na Figura 4, traz uma atualização mais completa dessas tendências após a posse de Donald Trump. Dentre os entrevistados republicanos ou simpatizantes, as afirmações que pontuam mais que a parcela democrata corre spondem a questões intimamente ligadas a aspectos nacionalistas: tomar medidas para proteger os EUA do terrorismo (84\%), proteger os empregos de trabalhadores americanos (81\%), manter a vantagem militar dos EUA sobre todas as outras nações (70\%) e reduzir a imigraçãoilegal para os EUA (68\%). Apesar de a primeira e a terceira afirmação corresponderem ao âmbito da segurança militar e estratégica, questões mais relacionadas ao protecionismo econômico no âmbito étnico e cultural se destacam nas outras duas afirmações.

Questões relacionadas ao fortalecimento militar e a promoção dos interesses econômicos dos Estados Unidos se destacam nas preferências republicanas, apontando para um protagonismo internacional da nação. Entretanto, esse protagonismovisa mais a manutenção do slogan America first do que de fato uma liderança ativa dos EUA. Há uma baixa adesão republicana quando analisadas questões relacionadas à promoção de valores (11\%), promover e defender direitos humanos (20\%) e auxiliar na melhoria do padrão de vida em outros países (12\%). Desde 2013, vem havendo uma queda constante nos três tópicos, sendo que o último apresentou a menor porcentagem desde a década de noventa (PEW RESEARCH CENTER, 2018).

Somada à vontade de ter menores responsabilidades, a redução do déficit comercial com outros países, antes uma questão de baixa prioridade, representou para 54\% dos republicanos um aspecto importante noúltimo ano, estando este em crescimento constante desde 1997. Além disso, ao mesmo tempo em que $56 \%$ dos republicanos concordam que outras nações assumam os custos na manutenção da ordem mundial, 51\% e 54\% dos republicanos entrevistados defendem que os EUA devem, respectivamente,promover negócios e interesses nacionais afora e diminuir o déficit comercial com outr os países. Em 1997esses dois últimos aspectos representavam, respectivamente, 23\% e 44\% do total. Logo, há uma priorização do fortalecimento econômico e militar nacional com o intuito de resguardar os Estados Unidos de responsabilidades que não afetem seus nacionais (PEW RESEARCH CENTER, 2018).

Antes de adentrarmos os aspectos práticos devemos priorizar o âmbito discursivo da administração Trump, buscando compreender se suas falas correspondem aos anseios popularese, posteriormente, se estão em sintonia com suas práticas governamentais. Dessa maneira, em matéria de política externa, o discurso do State of The Union apresenta-se como uma métrica mais adequada acerca do caráter discursivo de uma administração, uma vez que, desde1913, condensa 
as prioridades que um presidente visa comunicar à população e, especialmente, ao congresso no decorrer de um ano. Todavia, como não há a realização de um State of The Union no primeiro ano de cada mandato, também será utilizado o primeiro discurso presidencial realizado para os congressistas em 28 de fevereiro de 2017. Comparado às administrações anteriores, Donald Trump foi um dos presidentes que menos fez menções às palavras “o mundo, o globo e nações” desde a década de 1990 (PETULLA, 2018):

Defendemos as fronteiras de outras nações, deixando nossas próprias fronteiras abertas para qualquer pessoa atravessar e para que as drogas entrem em uma taxa agora sem precedentes. E gastamos trilhões e trilhões de dólares no exterior, enquanto nossa infraestrutura em casa desmoronou muito [...]. No momento, as empresas americanas são tributadas com uma das taxas mais altas do mundo. [...] Meu trabalho não é representar o mundo. Meu trabalho é representar os Estados Unidos da América (TRUMP, 2017, tradução nossa ${ }^{12}$ ).

Trump demonstra que os Estados Unidos ainda representam a hegemonia internacional, mas que está disposto a fazer com que outras nações também paguem pela sua parte na manutenção da ordem global (PETULLA, 2019) - estando em acordo com $56 \%$ da parcela republicana no mesmo tópico. Além disso, utilizou great mais vezes do que qualquer presidente no final doúltimo século e atualmente - somente perdendo para Reagan e, posteriormente, Nixon -, sendo uma alusãoà grandeza histórica da nação e de seu povo. Todavia é o pre sidente que menos fez uso das palavras "terrorismoe segurança” em seus discursos, indo contra a grande importância desse tópico para a população norte -americana - uma vez que $72 \%$ e $84 \%$ da população total e dos republicanos, respectivamente, consideram proteger os EUA contra o terrorismo como a maior prioridade da política externa.

No que tange "imigração e imigrantes", Trump, desde Woodrow Wilson em 1913, foi o presidente que, proporcionalmente, mais utilizou essas palavras em seus três pronunciamentos. Diferentemente de outros presidentes, $\mathrm{o}$ uso dessas palavras nos últimos três anos está mais associado aos custos econômicos, a segurança nacional e a proteção de empregos perante a imigração. Assim, transmite a ideia de que o sistema migratório nos EUA está ultrapassado e pouco meritocrático. Trump também foi o presidente que mais utilizou as palavras "muro" e "muros", as associando à necessidade de proteção nacional na fronteira com o México, atendendo aos anseios de $68 \%$ e $41 \%$ dos eleitores republicanos a favor da redução da imigração ilegal e legal, respectivamente (PETULLA, 2019).

Em meio a alta importância dada à proteção de empregos do povo americano - segunda prioridade de política externa para a população -, Trump, curiosamente, é um dos presidentes que menos utilizou as palavras "emprego, a economia e trabalhos” em seus discursos. Diferentemente de outras instâncias há uma visão mais positiva acerca dos índices de emprego, mas, ao mesmo tempo, há associações feitas com empregos perdidos por conta da im igração ilegal. Em relação à infraestrutura nacional, Trump discorre sobre um cenário pouco positivo, abordando uma infraestrutura nacional em frangalhos cujos recursos seriam direcionados para outras nações. Destarte, mesmo sendo o presidente que mais aborda esse tema desde Wilson, Donald Trump ainda cita poucas vezes a questão da infraestrutura nacional em comparação à demanda popular sobre essa questão (PETULLA, 2019). Apresentados os aspetos subjetivos da administração Trump, podemos discorrer acerca das mudanças práticas em sua política externa.

Historicamente, os Estados Unidos sempre tiveram uma política migratória complexa. Ronald Reagan, ao mesmo tempo em que negava asilo político para imigrantes, assinou o Immigration Reform and Control Act (IRCA) em 1986, que garantia anistia para mais de três milhões de imigrantes sem documentos que já viviam no país. Uma maior militarização da fronteira norte-americana deu-se início na administração de Bill Clinton, com a Operation Gatekeeper que dificultava o acesso pela fronteira com cercas triplas e a utilização de alta tecnologia infravermelha com sensores de calor corporal.

\footnotetext{
${ }^{12}$ We've defended the borders of other nations while leaving our own borders wide open for anyone to cross and for drugs to pour in at a now unprecedented rate. And we've spent trillions and trillions of dollars overseas, while our infrastructure at home has so badly crumbled. [...] Right now, American companies are taxed at one of the highest rates anywhere in the world. [...] My job is not to represent the world. My job is to represent the United States of America (TRUMP, 2017).
} 
Logo, as duas administrações seguintes deram continuidade ao mesmo movimento. Na administração Bush criou -se o Imigration and Customs Enforcement em2003, responsável por evitar crimes nas fronteiras, e teve, em 2006, a aprovação do Fence Act, que apontava para a criação de uma extensa cerca aolongo da fronteira ao sul do país. Apesar do Fence Act não ter sido financiado, contou com o apoio do então senador, Barack Obama (HING, 2019 apud PUBLIC RADIO INTERNATIONAL, 2019).

Enquanto presidente, Obama registrou recordes históricos nos números de deportações de imigrantes, contabilizando mais de 1 milhão de deportações em comparação com seu antecessor, que totalizaram 3.066.457 deportações em oito anos, além de dar início ao processo de detenção de famílias de imigrantes na fronteira. Até o momento, mesmo se observamos os números de deportações por ano, Obama ainda detém o recorde de 383.307, seguido por Trump com 275.725 por ano (NOWRASTEH, 2019).

Apesar de seu discurso agressivo, as políticas migratórias recentes encontram respaldo em uma base criada e fortificada ao longo de mais de duas décadas. No âmbito da imigração legal, há a tentativa de implementar diretrizes que limitem a concessão de green cards, priorizando uma parcela de imigrantes em melhor situação econômica, fluentes em inglês e bem qualificados, que reduziria de 1 milhão para 638 mil o número de green cards concedidos por ano e limitaria a residência permanente para 50 mil refugiados por ano. Dentre medidas tomadas para limitar a possibilidade de imigração, vale destacar também o travel ban de 2017, que impossibilitou a entrada de imigrantes, refugiados, turistas ou trabalhadores vindos do Chade, Iêmen, Síria, Irã, Líbia, Venezuela, Coreia do Norte e da Somália. Além disso, houve a tentativa de eliminar o DACA , a solicitação de redução de fundos federais para as cidades santuários (que não cooperam com as políticas migratórias federais), o corte no número de agentes governamentais que conduzem entrevistas de apuramento no exterior e a intensificação do processo de triagem para refugiados, duplicando o número de indivíduos caracterizados como "alto risco" e estendendo ainda mais o processo de triagem (AMADEO, 2017).

Até o momento, o número de refugiados reassentados no país caiu de 97 mil para 28 mil (PEW RESEARCH CENTER, 2017e) e, posteriormente, para 22 mil em 2018; e o número de imigrantes muçulmanos caiu de 38 mil para 22 mil entre 2016 e 2017. Mesmo não sendo um deporter in chief como Obama foi, a atual administração despende claros esforços na redução de imigrantes legais e ilegais no país, mesmo que isso afete negativamente a composição da força de trabalho norte-americana (AMADEO, 2014).

No que tange à política comercial, há uma clara tentativa de corresponder às expectativas protecionistas da população do país. A saída do Tratado Trans Pacífico sob o pretexto de privilegiar a reativação da indústria nacional representabem a migração para uma participação mais protecionista no comércio exterior. O atual impasse comercial com a China, o fim do NAFTA e a pendência da aprovação do USMCA - apresentado como um novo acordo que privilegiará a indústria automotiva nacional - também são justificados pela mesma motivação. Todavia, estudos demonstram que, mesmo aparentando protegerem a economia, a indústria e o trabalhador nacional, essas medidas podem acarretar, a longo prazo, em uma desaceleração da economia. Há desincentivo para empresas estrangeir as e dificuldade de reestruturação da produção industrial no país e no repasse de custos para o consumidor norte-americano, já que no caso da guerra comercial há uma elevação dos preços de importados (LOBOSCO, 2019; UNCTAD, 2019). 
Imagem 3: Prioridades na política externa entre Democratas e Republicanos.

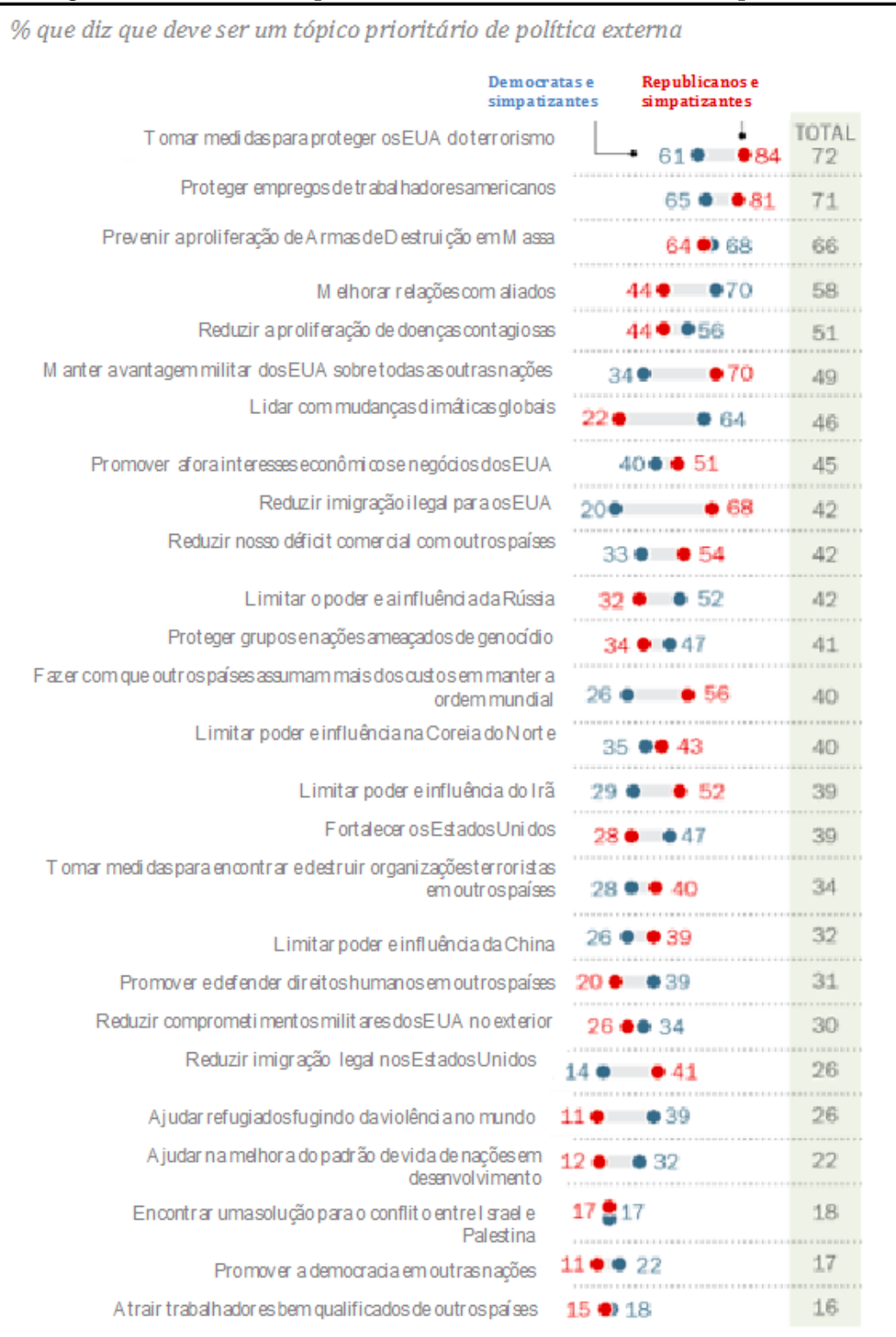

Fonte: Adaptado pelos autores, com base em Pew Research Center (2018).

O multilateralismo também se apresenta como uma distinção notória de Trump perante seus antecessores. A saída dos Estados Unidos da UNESCO e do Conselho de Direitos Humanos da Organização das Nações Unidas correspondem às expectativas republicanas e conservadoras de não priorizar a promoção de direitos humanos em outras nações. Todavia, a saída de ambos os órgãos possui um denominador em comum: Israel. No âmbito da UNESCO, curiosamente, nãoé a primeira vez que que os EUA deixam o órgão. Em 1984, durante o governo Reagan, a saída justificou se pela adesão volumosa de novos membros, fazendo com que a influência norte-americana fosse perdida e que novas prioridades fossem criadas, distanciando-se dos objetivos de nações mais desenvolvidas e tornando a permanência na organização um estorvo (WAXMAN, 2017).

Após o retorno dos Estados Unidos em 2002 e uma comoção perante a situação do 11 de setembro do ano anterior, o trabalho da organização alinhou-se com a guerra ao terror do período ao auxiliar na reconstrução e preservação de monumentos históricos em zonas de conflito. O anuncio da saída em outubro de 2017 também remete a questões de perda de influência, e até mesmo de interesse, mas a justificativa apresentada corresponde ao viés negativo da UNESCO contra Israel, que teria se tornando uma organização extremamente politizada, contra a sociedade livre, o livre mercado, a imprensa livre e com um orçamento expansivo (WAXMAN, 2017). 
Em relação ao Conselho de Direitos Humanos, a saída também fora justificada comoum descontentamento com as constantes críticas feitas aos israelenses em relação ao conflito palestino no conselho. Além disso, somou -se a questão de que essas críticas vinham de nações que desrespeitavam constantemente direitos humanos em suas próprias nações e que ganhavam mais espaço e protagonismo, como a China, Venezuela, Arábia Saudita, Catar, Emirados Árabes Unidos, dentre outros. No pronunciamento acerca da decisão, a antiga Embaixadora dos Estados Unidos na ONU, Nikki Haley, argumentou que caso o Conselho de Direitos Humanos deve mudar suas diretrizes caso busque corres ponder a uma organização na qual o país possa confiar para proteger e promover os direitos humanos. Caso a mudança não ocorra, os EUA deverão buscar o avanço dos direitos humanos fora do conselho (DWYER, 2018, tradução nossa). Em ambos os casos, duas conclusões decorrem: [1] mesmo reconhecendo a necessidade da reforma de organizações, os Estados Unidos atualmente opta por abandoná-las ao invés de ser o protagonista dessas mudanças e [2] há uma clara reaproximação de Israel - uma nação altamente nacionalista no âmbito doméstico e externo -, não somente justificada por essas atitudes, mas pela proximidade de Trump com o primeiro-ministro Benjamin Netanyahu e da mudança da embaixada americana para Jerusalém.

O distanciamento do multilateralismo continua na áre a de regimes internacionais, representado pela saída do Acordo de Paris e do acordo nuclear com o Irã em 2017, e o distanciamento de aliados históricos, no caso da União Europeia - ambas sendo questões que correspondem às expectativas de uma parcela expres siva da população e ao aspecto discursivo da administração. Seja como uma medida retaliativa em relação a administração Obama ou o cumprimento de uma promessa eleitoral, a saída desses dois acordos demonstra a tendência da administração em não adentrar regimes que resultem em compromissos que limitem suas ações e que deem vantagem a nações que, uma vez inimigos históricos, ainda devem ser tratadas como tal - sendo exemplos recentes o caso do Irã e a retração na retomada das relações com Cuba (HALTIWANGER, 2019). Consequentemente, as relações com a União Europeia são afetadas frente esse distanciamento do multilateralismo, e Trump, como demonstrou em atritos recorrentes com Mácron e Merkel, não se constrange em acenar para outros líderes “controversos”, comoJair Bolsonaro e Viktor Orbán da Hungria (PETTI, 2019)

O último aspecto prático que merece maior atenção corresponde a presença militar dos Estados Unidos no exterior. Trump, no decorrer de sua campanha, sempre fez críticas contundentes acerca de intervenções norte-americanas em outros Estados, como no caso do Iraque em 2003 e da Líbia em 2011, sinalizandouma política exterior mais contida e menos preocupada com questões de outras nações. Todavia, sua administração, ao mesmo tempo em que sinaliza para um isolamento, ainda aspira um papel ativo em questões se segurança internacional. Os dois ataques a bases militares do regime de Bashar al-Assad, em 2017 e 2018, a morte do líder do Estado Islâmico, Abu Bakr al -Baghdad, em uma operação militar em outubro de 2019 e o caso das disputas e tentativa de reconciliação com a Coreia do Norte, demonstram que os Estados Unidos ainda buscam se impor militarmente em aspectos ligados a segurança internacional. Todas essas questões podem ser justificadas como contenção de ameaças exteriores que podem, futuramente, afetar diretamente a segurança nacional (COUNCIL ON FOREIGN RELATIONS, 2019). A retirada das tropas norte -americanas do norte da Síria, por mais que sinalize uma retração da atividade militar no exterior, corresponde mais a uma tendência nas últimas décadas do que a uma peculiaridade da administração atual, como demonstra a Figura 4. 
Imagem 4: Presença militarinternacional dos Estados Unidos.

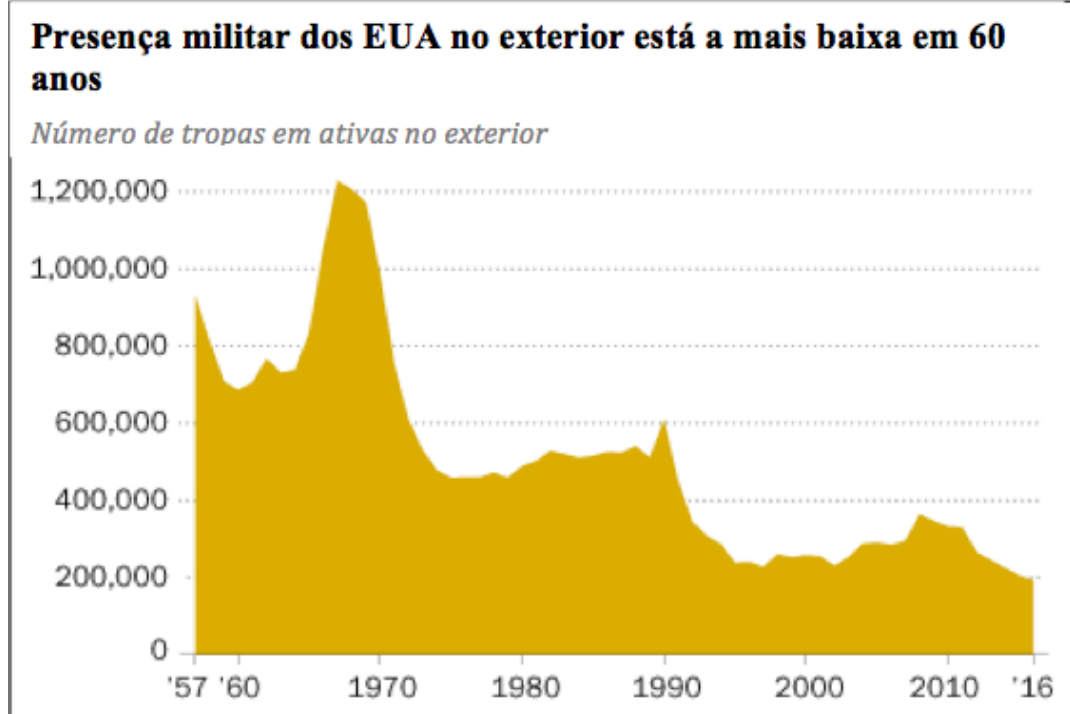

Fonte: Elaborado pelos autores, com base em Bialik (2017).

Ainda há sinais de ações pontuais dos Estados Unidos no cenário internacional, que busca justamente se eximir de compromissos formais. Nesse aspecto, Trump visa corresponder às expectativas de reduzir os comprometimentos militares ao criticar a utilidade da Organização do Tratado do Atlântico Norte (OTAN), seus custos elevados e a baixa quantia gasta por outros Estados-membros e, consequentemente, ameaça retirar o país do bloco (BARNES; COOPER, 2019).

Logo, sua política externa destoa nitidamente em alguns aspectos quando comparado com outras administrações - menos acanhada em transmitir valores mais nacionalistas em suas ações. Diferentemente do aspecto dom éstico, na esfera internacional o nacionalismo econômico se apresenta não mais como um último recurso de soluções de conflitos, mas como uma ferramenta mais importante do que o multilateralismo. Como abordado anteriormente, Trump, mais do que seus antecessores, almeja deter um freedom of action genuíno, colocando os interesses nacionais em primeiro lugar, sendo o nacionalismo econômico seu principal poder de barganha.

O mundo livre deve abraçar suas fundações nacionais. Não deve tentar apagá-las ou substituí-las [...].Se você quiser liberdade, orgulhe - se do seu país. Se você quer democracia, mantenha sua soberania. E se você quer paz, ame sua nação. Líderes sábios sempre colocam o bem de seu próprio povo e de seu próprio país em primeiro lugar. O futuro não pertence aos globalistas. O futuro pertence aos patriotas (TRUMP, 2019, tradução nossa ${ }^{13}$ ).

\section{Conclusão}

Frente a flexibilização de fluxos transfronteiriços, identidades nacionais são alteradas e, em alguns casos, fortemente transformadas, podendo resultar na ascensão de sentimentos nacionalistas. Donald Trump não somente foi capaz de identificar a existência desses sentimentos nacionalistas, mas também de potencializá -los, e buscou fidelizar e alienar sua base de apoio. Nesse aspecto, a instrumentalização de elementos nacionalistas serve comouma ferramenta de capital político, uma vez que pode passar a “ditar as regras do jogo político”. Antigos aliados podem se transformar em inimigos, contradições podem ser solucionadas com base no apelo à elementos nacionais subjetivos e instituições podem ser minadas sob a justificativa de serem falhas e ineficientes.

\footnotetext{
${ }^{13}$ The free world must embrace its national foundations. It must not attempt to erase them or replace them [...]. If you want fr eedom, take pride in your country. If you want democracy, hold on to your sovereignty. And if you want peace, love your nation. Wise leaders always put the good of their own people and their own country first. The future does not belong to globalists. The future belongs to patriOts (TRUMP, 2019).
} 
A derrota de Trump nas urnas em 2020, contudo, não desqualifica a força do sentimento nacionalista apresentado nesse trabalho, uma vez que, com a negação por parte do republicano em aceitar os resultados das urnas, sua base de apoiadores se mobilizou contra as próprias instituições do país, deslegitimando os resultados eleitorais, a decisão de juizados estaduais e a legitimidade do presidente eleito, Joe Biden. Com incentivo prévio de Trump, no dia 6 de dezembro de 2021, a invasão ao Capitólio representou o ápice da força dos sentimentos nacionalistas potencializados ao longo dos últimos quatro anos, justamente por apoiadores de Trump ao tentarem impedir a certificação da vitória de Biden por meio de uma tentativa golpista frustrada.

Não seria a primeira vez no século na qual o patriotismo norte-americano despontou para um nacionalismo mais ardente - os eventos do pós-11 de setembro são um exemplo recente. Contudo, a novidade corresponde aos aspectos nacionalistas que essa nova onda valoriza. No âmbito doméstico, está ligada a valorização maior de aspectos étnicos e culturais no que tange o sentimento nacional. No campo da política externa há um redirecionamento de algumas prioridades da atual administração e a potencialização de tendências anteriores. A securitização da imigração ganha uma nova roupagem com a administração Trump, unindo questões de segurança nacional, economia nacional e aspectos étnicos e culturais. Apesar de redirecionamentos na área comercial, ainda seria cedo afirmar que ocorreram mudanças drásticas no curso histórico da política comercial dos EUA. Destarte, a tendência que mais se destaca é o afastamento do multilateralismo e a aproximação de um bilateralismo pautado no nacionalismo econômico agressivo, mais direcionado contra oponentes, mas que, comovisto, pode também ser utilizado contra antigos aliados.

Assim, por sua formação histórica, o nacionalismo e o patriotismo são elementos que devem ser levados em consideraçãona construção discursiva e prática da política exterior dos Estados Unidos. No caso da administração atual, a expressão no commitments define bem as dinâmicas de sua política externa em diver sas áreas. Se na prática ela se origina por questões pragmáticas ou ideológicas, ou ambas, seria difícil afirmar com veemência, mas seu aspecto discursivo e a percepção popular claramente se justificam por questões relacionadas a um national pride mais agressivo e cultural. É justamente por isso que esse trabalho buscou também elucidar as diferenças entre nacionalismo e patriotismo, uma vez que são elementos que caminham juntos na história norte-americana e que, talvez por questões semânticas, o nacionalismo acaba por ser um termo "guarda-chuva" para patriotismo-o que deve ser evitado.

O caráter subjetivo está presente em toda e qualquer política exterior de uma nação, não sendo diferente no caso norte-americano, uma vez que, como a história nos demonstra, uma ação no exterior é construída e legitimada perante uma justificativa, plausível ou não. Donald Trump parece compreender esse aspecto subjetivo do discurso na esfera política, e praticou uma dinâmica de ação e reação com sua base de apoiadores na construção desse novo nacionalismo. Cabe observarmos se está o futuro, ou somente o período da administração de Trump, reservado aos nacionalistas.

\section{Referências}

AMADEO, Kimberly. Donald Trump on Immigration, Pros and Cons of His Policies. The Balance, [s. l.], 19 Sep. 2017. Disponível em: https://www.thebalance.com/donald-trump-immigration-impact-on-economy-4151107. Acesso em:20 Nov. 2019.

AMADEO, Kimberly. What Is the North American Free Trade Agreement? The Balance, [s. l.], 28 Oct. 2014. Disponível em: https://www.thebalance.com/nafta-definition-north-american-free-trade-agreement-3306147. Acesso em:22 Nov. 2019.

ANDERSON, BENNEDICT. Comunidades imaginadas. 1 ed. São Paulo: Companhia das Letras, 2008, 336 p.

BAKER, Peter. 'Use That Word!': Trump Embraces the 'Nationalist' Label. The New York Times, [s. l.], 23 Oct. 2018. U.S. Disponível em: https:/www.nytimes.com/2018/10/23/us/politics/nationalist-president-trump.html. Acesso em:20 Jun. 2019.

BARNES, Julian E; COOPER, Helene. Trump Discussed Pulling U.S. From NATO, Aides Say Amid New Concerns Over Russia. The New York Times, [s.l.], 15 Jan. 2019. Disponível em: https://www.nytimes.com/2019/01/14/us/politics/nato-president-trump.html. Acesso em: 24 Nov. 2019. 
BENDER, MICHAEL. Trump's Rallies Aren't a Sideshow. They Are the Campaign. The Wall Street Journal [s. I.] 22, Oct. 2019. Disponível em: <https://www.wsj.com/articles/trumps-rallies-arent-just-part-of-his-campaign-they-are-the-campaign$11571753199>$ Acesso em: 7 Out. de 2020.

BIALIK, Kristen. U.S. active-duty military presence overseas is at its smallest in decades. [S. l.]: Pew Research Center, 2017. Disponível em: https://www.pewresearch.org/fact-tank/2017/08/22/u-s-active-duty-military-presence-overseas-is-at-its-smallestin-decades/.Acesso em: 24 Nov. 2019.

BONIKOWSKI, Bart; DIMAGgIO, Paul.Varieties of American Popular Nationalism. American Sociological Review, [s.l.], v. 81, n. 5, p. 949-980,2016. Disponível em: https://doi.org/10.1177/0003122416663683. Acesso em: 20 Nov. 2019.

BUCHHOLZ, Katharina. Infographic: How Trump Talks About Immigrants. Statista Infographics, [s. l.], 2019. Disponível em: https://www.statista.com/chart/18977/trump-language-towards-immigration-rallies/

BULLA, Beatriz; LEOPOLDO, Ricardo. Eduardo Bolsonaro se encontra com Steve Bannon em Nova Iorque. [S.l.] Estadão, 2019. Disponível em: https://internacional.estadao.com.br/noticias/geral,eduardo-bolsonaro-se-encontra-com-steve-bannon-em-novayork,70003022266. Acesso em: 7 Out. 2019.

BURRI, Mira. Cultural Protectionism 2.0: Updating Cultural Policy Tools for the Digital Age. In:TRANSNATIONAL CULTURE IN THE INTERNET AGE. [S. l.]: Edward Elgar, 2012.

COUNCIL ON FOREIGN RELATIONS. Trump's Foreign Policy MomentsCouncil on Foreign Relations. [S. l.]: Council on Foreign Relations, 2000. Disponível em: https://www.cfr.org/timeline/trumps-foreign-policy-moments. Acesso em: 24 Jun. 2019.

COX, Daniel et al. Beyond Economics: Fears of Cultural Displacement Pushed the White Working Class to Trump | PRRI/The Atlantic ReportPRRI. [S. l.]: PRRI/The Atlantic Report, 2019. Disponível em: https://www.prri.org/research/white -working-classattitudes-economy-trade-immigration-election-donald-trump/.Acesso em:19Jun. 2019.

DIAMOND, Jeremy. Trump jokes after rally attendee's suggestion to "shoot" migrants at the border. CNN, [s. l.], 9 May 2019. Disponível em: https://edition.cnn.com/2019/05/09/politics/donald-trump-rally-shoot-migrants/index.html. Acesso em: 7 Out. 2020 .

DOHERTY, Carol. Mixed verdict from public on America's global standing. Pew Research Center, [s. l.], 27 May 2018. Disponível em: https://www.pewresearch.org/fact-tank/2016/05/27/mixed-verdict-from-public-on-americas-global-standing. Acesso em: 4 Nov. 2019.

DUECK, Colin. What Is Conservative American Nationalism? National Review, [s. l.], 21 Oct. 2019. Disponível em: https://www.nationalreview.com/2019/10/what-is-conservative-american-nationalism/. Acesso em: 25 Nov. 2019.

DWYER, Colin. U.S. Announces Its Withdrawal From U.N. Human Rights Council. NPR, [s. l.], 19 Jun. 2018. Disponível em: https://www.npr.org/2018/06/19/621435225/u-s-announces-its-withdrawal-from-u-n-s-human-rights-council. Acesso em: 23 Nov. 2019.

FEDERAL RESERVE HISTORY. Creation of the Bretton Woods System. Federal Reserve System, [s.l.], 22 Nov. 2013. Disponível em:< https://www.federalreservehistory.org/essays/bretton-woods-created> Acesso em 14 Jan. 2021.

FINKEL, Matt. Theories of Nationalism: A Brief Comparison of Realist and Constructivist Ideas of the Nation. Inquiries Journal, [s. l.], v. 8, n. 10,2016. Disponível em: http://www.inquiriesjournal.com/articles/1460/theories - of-nationalism-a-brief-comparison-ofrealist-and-constructivist-ideas-of-the-nation. Acesso em: 5 Out. 2020.

FRAZIN, Rachel. "Lock her up” chant breaks out at Trump rally. The Hill, [s. l.], 1 Aug. 2019. Disponível em: https://thehill.com/homenews/campaign/455874-lock-her-up-chant-breaks-out-at-trump-rally. Acesso em:7 Out. 2020.

FULLER, Graham. America's Uncomfortable Relationship With Nationalism. The Stanley Foundation Policy Analysis Brief, [s. l.], 2006. Disponível em: https://stanleycenter.org/publications/americas - uncomfortable-relationship-with-nationalism/. Acesso em: 26 Out. 2020.

GLADDING, Ian. Rise of Economic Nationalism and Its Implications | Faculty Forum. In: LEWIS UNIVERSITY FACULTY FORUM. 25 Apr. 2018. Disponível em: https://www.lewisu.edu/experts/wordpress/index.php/rise - of-economic-nationalism-and-itsimplications/. Acesso em: 7 Out. 2020.

HALTIWANGER,John. The Iran nuclear deal: Here's what you need to know - Business Insider. Business Insider, [s. l.], 19 Sep. 2019. Disponível em: https://www.businessinsider.com/iran-nuclear-deal-explained.Acesso em: 23 Nov. 2019.

HARVARD T. H. CHAN SCHOOL OF PUBLIC HEALTH;NPR. DISCRIMINATION IN AMERICA: FINAL SUMMARY. [S. l.: s. $n$.], 2018. Disponível em: https://cdn1.sph.harvard.edu/wp-content/uploads/sites/94/2018/01/NPR-RWJF-HSPH-Discrimination-FinalSummary.pdf. Acesso em: 21 Jun. 2019. 
HOBSBAWM, ERIC. Nações e Nacionalismo desde 1780. Rio de Janeiro: Editora Paze Terra. 1991,230 p.

HUTCHINSON,J; SMITH, A. Nationalism. New York: Oxford University Press. 1994, 380 p.

JONES, Jeffrey M. In U.S., Record-Low 47\% Extremely Proud to Be Americans. Gallup, [s. l.], 2 Jul. 2018. Disponível em: https://news.gallup.com/poll/236420/record-low-extremely-proud-americans.aspx. Acesso em: 8 Jun. 2019.

LAMBERT, Brian. Trump calls Democrats 'party of crime' during Minnesota rally. MinnPost, [s. l.], 5 Oct. 2018. Disponível em: https://www.minnpost.com/glean/2018/10/trump-calls-democrats-party-of-crime-during-minnesota-rally/. Acesso em: 26 Out. 2020.

LEVIN, Bess. Trump Goes Full White Supremacist at Minnesota Campaign Rally. Vanity Fair, [s. l.], 1 Oct. 2020. Disponível em: https://www.vanityfair.com/news/2020/10/donald-trump-minnesota-racist. Acesso em: 26 Out. 2020.

LIEVE, A. America Right Or Wrong: An Anatomy of American Nationalism. 2 ed. New York: Oxford University Press. 2012 , 312 p.

LOBOSCO, Katie. Trump's NAFTA replacement isn't enough for striking auto workers. CNN, [s. l.], 17 Sep. 2019. Disponível em: https://edition.cnn.com/2019/09/17/politics/nafta-usmca-gm-strike/index.html. Acesso em:22 Nov. 2019.

MANNING, Robert A. Trump's Globalism Is a Caricature of Multilateralism. Foreign Policy, [s. l.], 2019. Disponível em: https://foreignpolicy.com/2019/10/02/trumps-globalism-is-a-caricature-of-multilateralism. Acesso emt: 7 Out. 2020.

MCCARTNEY, PAUL T. American Nationalism and U.S. Foreign Policy from September 11 to the Iraq War. Political Science Quarterly, [s. l.], v. 119, n. 3, p. 399-423, 2004. Disponível em: https://doi.org/10.2307/20202389. Acesso em: 15 Out. 2020.

MOTYL, A. Encyclopedia of Nationalism: Leader, Movements and Concepts. Florida: Academic Press, v. 2, 2000,621 p.

NIELSEN, K. Cultural nationalism, neither ethnic nor civic. The Philosophical Forum, Albany: State University of New York Press. 1999.

NOWRASTEH, Alex. Deportation Rates in Historical Perspective. Cato Institute, [s. l.], 16 Sep. 2019. Disponível em: https://www.cato.org/blog/deportation-rates-historical-perspective. Acesso em: 22 Nov. 2019.

PETTI, Matthew. Trump Airs Nationalism and Globalism Gripes at the UN. The National Interest, [s. l.], 2019. Disponível em: https://nationalinterest.org/feature/trump-airs-nationalism-and-globalism-gripes-un-83171. Acesso em: 23 Nov. 2019.

PETULLA, Sam. How Trump's compares with 100 years of speeches. CNN, [s. l.], 6 Feb. 2019. Disponível em:

https:/edition.cnn.com/2018/01/30/politics/trump-state-of-the-union-in-history-100-years/index.html. Acesso em: 20 Nov. 2019.

PEW RESEARCH CENTER. 4. Race, immigration and discrimination. [S. l.]: Pew Research Center for the People and the Press, 2017c. Disponível em: https://www.people-press.org/2017/10/05/4-race-immigration-and-discrimination/. Acesso em: 20 Jun. 2019.

PEW RESEARCH CENTER. Conflicting Partisan Priorities for U.S. Foreign Policy. [S. l.]: Pew Research Center for the People and the Press, 2018. Disponível em: https:/www.people-press.org/2018/11/29/conflicting-partisan-priorities-for-u-s-foreign-policy/. Acesso em: 7 Nov. 2019.

PEW RESEARCH CENTER. Political typology: Race and discrimination, opinions about immigrants and Islam. [S. $l$.]: Pew Research Center for the People and the Press, 2017a. Disponível em: https://www.people-press.org/2017/10/24/6-race-anddiscrimination-opinions-about-immigrants-and-islam/.Acesso em: 4 Jun. 2019.

PEW RESEARCH CENTER. Key findings on Americans' views of race in 2019. [S. l.]: Pew Research Center for the People and the Press, 2019. Disponível em: https:/www.pewresearch.org/fact-tank/2019/04/09/key-findings-on-americans-views-of-race-in-2019/. Acesso em: 21 Jun. 2019.

PEW RESEARCH CENTER. America Admits Fewer Refugees as Number Displaced Grows Globally. [S. $l$.]: Pew Research Center for the People and the Press, 2017e. Disponível em: https://www.pewresearch.org/global/2017/10/12/u -s-resettles-fewer-refugees-evenas-global-number-of-displaced-people-grows/.Acesso em: 22 Nov. 2019.

PEW RESEARCH CENTER. The World Facing Trump: Public Sees ISIS, Cyberattacks, North Korea as Top Threats. [S.l.]: Pew Research Center for the People and the Press, 2017d. Disponível em: https://www.people-press.org/2017/01/12/the-world-facingtrump-public-sees-isis-cyberattacks-north-korea-as-top-threats/.Acesso em: 5 Nov. 2019.

PEW RESEARCH CENTER. How Countries Around the World View National IdentityPew Research Center's Global Attitudes Project. [S. l.]: Pew Research Center for the People and the Press, 2017b. Disponível em: https://www.pewresearch.org/global/2017/02/01/what-it-takes-to-truly-be-one-of-us/.Acesso em: 20 Jun. 2019. 
PUBLIC RADIO INTERNATIONAL. Trump's hard-line immigration policies build on the history of former US presidents. Public Radio International, [s. l.], 2019. Disponível em:https:/www.pri.org/stories/2019-07-12/trumps-hard-line-immigration-policies-buildhistory-former-us-presidents. Acesso em: 22 Nov. 2019.

RENSHON, Stanley. Multiculturalism in the U.S.: Cultural Narcissism and the Politics of Recognition. CIS, [s. l.], Jun. 2017. Disponível em: https://cis.org/Renshon/Multiculturalism-US-Cultural-Narcissism-and-Politics-Recognition. Acesso em: 4 Jun. 2019.

SAAD, Lydia. Americans Say Economy Is “Most Important Thing Going Well”Gallup. [S. l.]: Gallup, 2018. Disponível em: https://news.gallup.com/poll/237596/americans-say-economy-important-thing-going.aspx. Acesso em: 20 Jun. 2019.

TRUMP, Donald. Remarks by President Trump in Joint Address to Congress. [S. l.]: The White House, 2017. Disponível em: https://www.whitehouse.gov/briefings-statements/remarks-president-trump-joint-address-congress/.Acesso em: 20 Nov. 2019.

TRUMP, Donald. Remarks by President Trump to the 74th Session of the United Nations General Assembly. [S. l.: s. n.], 2019. Disponível em: https://www.whitehouse.gov/briefings-statements/remarks-president-trump-74th-session-united-nations-generalassembly/. Acesso em: 24 Nov. 2019.

UNCTAD. Trade war leaves both US and China worse off. United Nations Conference on Trade and Development, [s. l.], 2019. Disponível em: https://unctad.org/en/pages/newsdetails.aspx?OriginalVersionID=2226. Acesso em: 22 Nov. 2019.

US DEPARTMENT OF HOMELAND SECURITY. Deferred Action for Childhood Arrivals (DACA)Department of Homeland Security, 23 jun. 2018. Disponível em: https://www.dhs.gov/deferred-action-childhood-arrivals-daca. Acesso em: 22 Nov. 2019.

WAXMAN, Olivia. The U.S. Has Left UNESCO Before. Here's Why. Time, [s. l.], 2017. Disponível em: https://time.com/4980034/unesco-trump-us-leaving-history/. Acesso em: 23 Nov. 2019.

WOLF, Zachary B. 9 ways Trump has shredded US institutions. CNN, [s. l.], 31 May 2019. Disponível em: https://edition.cnn.com/2019/05/31/politics/trump-shred-democratic-institutions/index.html. Acesso em: 7 Out. 2020.

\begin{tabular}{ll}
\hline Funções de colaboração exercidas & \\
\hline Thiago Godoy Gomes de Oliveira: & $\begin{array}{l}\text { Conceituação; Metodologia; Validação; Curadoria de dados; Administração do projeto; Visualização; Análise formal; } \\
\text { Investigação; Escrita (primeira redação); Escrita (revisão e edição); }\end{array}$ \\
Lucas Amaral Batista Leite: & $\begin{array}{l}\text { Conceituação; Metodologia; Validação; Administração do projeto; Visualização; Análise formal; Supervisão; Escrita (revisão e } \\
\text { ediça); }\end{array}$ \\
\hline
\end{tabular}

Informaçôes fornecidas pelos(as) autores(as) de acordo com a Taxonomia de Funçôes de Colaborador (CRediT) 